\title{
O sexo dos tubarões, de Naná DeLuca, ou uma escrita que faz delirar
}

\author{
Leocádia Aparecida Chaves*
}

A cada vez, olhar melhor. E falhar melhor na tarefa impossivel de conhecer os infinitos particulares. Naná DeLuca

Ao analisar a produção literária de Franz Kafka (1883-1924), escritor judeu austro-húngaro, e suas reflexões sobre o escrever na língua alemã - a língua do Outro -, Gilles Deleuze e Félix Guattari (1977, p. 25) postulam: "Uma literatura menor não é a de uma língua menor, mas antes a que uma minoria faz em uma língua maior". Por meio desse enquadramento analítico é possível pensar tanto a artesania do escritor no manejo com a língua do Outro quanto seu engajamento político para inventar um povo que falta em sua obra. Nessa perspectiva, segundo os autores, a arquitetura do texto literário é constituída por três elementos, que conjugados entre si, fazem nascer uma escrita estrangeira, uma escrita própria capaz de fazer delirar seu opressor e por esse meio escapar do sistema dominante: um forte coeficiente de modificação da língua maior; um vínculo com o imediato político; e uma enunciação individual que mobiliza o agenciamento coletivo. O menor, então, emerge em oposição ao maior - opressor - e, nesse sentido, revela-se como um devir-revolucionário, delirante (Deleuze; Guattari, 1977).

Trata-se, portanto, de uma perspectiva potente para analisarmos o romance O sexo dos tubarões, de Naná DeLuca (2017), ainda que o contexto de sua produção e as questões que atravessam sua escrita e a instância de sua autoria se distanciem da kafkiana. ${ }^{1}$

Kafka produziu sua literatura num contexto em que havia, explicitamente, um projeto antissemita vinculado à expansão e dominação alemã no leste europeu (Oelsner, 2017). DeLuca, por sua vez, ao se reconhecer como pessoa transgênera ${ }^{2}$

\footnotetext{
Doutoranda no Programa de Pós-Graduação em Literatura e Práticas Sociais da Universidade de Brasília (UnB), Brasília, DF, Brasil. E-mail: leocadiachaves@gmail.com.

1 Este artigo é um desdobramento das reflexões apresentadas por meio de uma comunicação, de mesmo título, no Congresso Internacional da Associação Brasileira de Literatura Comparada (ABRALIC), realizado em 2018, em Uberlândia.

2 O termo genérico transgênero refere-se à condição de uma pessoa não se identificar com o gênero designado no seu nascimento, que em nossa sociedade se vincula compulsoriamente com o sexo biológico. Esse grupo pode incluir, por exemplo, pessoas travestis e transexuais (ver JEsus, 2012).
} 
não binária, ${ }^{3}$ vincula-se a um povo identificado como minoria, formado por pessoas que, ao contrariarem a compulsoriedade binária sexo-gênero, colocam em xeque um padrão normativo historicamente construído pelos dispositivos de poder (ButLER, 2017). Assim, ao existirem como se reconhecem, agem como fraturadores da matriz identitária cisheterocentrada, ${ }^{4}$ pilar perpetuador do patriarcado e, por isso, reconhecidos socialmente como abjetos, perversos: corpos matáveis e insacrificáveis (BUTLER, 2001, 2015).

Essa realidade social tem sido denunciada como de exceção para essa população (Jesus, 2013; MомваÇA, 2018), uma vez que o Estado brasileiro - a despeito do avanço normativo quanto a sua despatologizaçãa $0^{5}-$ tem, por meio de dispositivos objetivos e subjetivos (ZIzEK, 2013), "trabalhado" ferozmente para perpetuar o seu genocídio em nosso país.

Em confirmação, o relatório Violências contra pessoas lésbicas, gays, bissexuais, trans e intersexo nas Américas, produzido pela Comissão Interamericana de Direitos Humanos (CIHD, 2015), denuncia que esse povo enfrenta, em todos os espaços e o tempo todo, uma violência generalizada e contextualizada, na qual a motivação do perpetrador deve ser entendida como um fenômeno complexo ${ }^{6}$ e multifacetado, e não apenas como um ato individual. Já o relatório Assassinatos de LGBT no Brasil (GGB, 2017) denuncia que, em 2016, a cada 25 horas um LGBT foi assassinado no país.

Portanto, ainda que os contextos e as questões vivenciadas por esses autores guardem especificidades, acreditamos que o altericidio, perpetrado pela ordem tanto no contexto kafkiano quanto no de DeLuca, será igualmente revelado e subvertido em suas produções literárias.

3 Quanto à identificação como pessoa transgênera não binária: "além de transgredirem à imposição social dada no nascimento, ultrapassam os limites dos polos e se fixam ou fluem em diversos pontos da linha que os liga, ou mesmo se distanciam da mesma. Ou seja, indivíduos que não serão exclusiva e totalmente mulher ou exclusiva e totalmente homem, mas que irão permear em diferentes formas de neutralidade, ambiguidade, multiplicidade, parcialidade, ageneridade, outrogeneridade, fluidez em suas identificações (Reis; Pinho, 2016, p. 14). Portanto, em respeito ao autorreconhecimento de Naná DeLuca como pessoa transgênera não binária, vamos nos referir a sua pessoa, usando pronomes neutros, masculino e feminino.

4 Em nossa sociedade, a identificação cisgênera aplica-se a pessoas que se identificam com o gênero com o qual foram compulsoriamente associadas, no nascimento, em função do sexo biológico (JEsUS, 2012), que ao longo da história ocidental também formatou um padrão quanto à orientação sexual, o da heterossexualidade (Jesus, 2012; Butler, 2017). Para pensar sobre a construção do padrão cisgênero, consultar o artigo $O$ cis pelo trans, de Amara Moira Rodovalho (2017).

5 Salientamos que o Supremo Tribunal Federal, por meio da Ação Direta de Inconstitucionalidade (ADI) $\mathrm{n}^{\circ} 4.275$, reconheceu, em $1^{\circ}$ de março de 2018 , que transexuais e transgêneros têm o direito de alterar, via procedimento cartorial, prenome e gênero no registro civil sem a necessidade de realização de cirurgia de mudança de sexo, bem como ato ou laudos médicos e psicológicos, uma vez que a identidade é autodefinida pela própria pessoa.

6 Como o relatório registra, esses números são subnotificados, pois não há estatísticas governamentais sobre crimes de ódio em nosso país. Os dados que existem se baseiam em notícias publicadas na mídia, internet e informações pessoais. 
Aqui nos é permitido pensar a relação entre a instância da autoria em uma sociedade transfóbica ${ }^{7}$ e a criação de seu povo no espaço romanesco. Criação que se efetiva por meio dos três elementos indicados pela postulação deleuziana: manejo de modo delirante da língua maior - portuguesa brasileira cisheteronormativa; vínculo com o imediato político; e uma enunciação individual que mobiliza o agenciamento coletivo. Esse manejo da língua/linguagem dá-se num forte processo de reterritorialização tanto no que diz quanto no como diz, uma vez que surge da fratura de múltiplos binários para acolher corpos, desejos, dores e traumas de existências que ainda faltam na literatura maior (Deleuze; GUATARRI, 1977).

Essa literatura nasce, então, para ouvir e permitir falar uma protagonista trans não binária, não nomeada, porque muitas e muitos: uma criança humana - tubarão -, que, desde a mais tenra infância, sofre violências múltiplas por existir como se entende, sofre o desconforto de existir solitariamente por não saber de outros iguais a ela:

O homem atacou a criança. E, então ela não tinha mais a força de controlar elementos. Era fraca. Não tinha poder algum e sentia como se nunca o tivesse tido. Era a mais fraca das criações do mundo. Que dor naquele instante, criança e tubarão. Sofria estatelada a criança. Fraca. [...] Violência cantava aquele refrão. O homem fez tanta dor que a criança alucinou que não sentia mais dor alguma. A criança não sabia lutar. $\mathrm{O}$ tubarão, no entanto, sabia (DeLucA, 2017, p. 25-26).

Desse modo, a narrativa traz para a superfície o protagonismo de uma criança que embora maculada pela crueldade do homem, signo de discursos e práticas do patriarcado (BUTLER, 2017), encontra força para (re)existir enquanto tubarão: uma forma historicamente lida pelos humanos como monstruosidade, mas que por meio da escrita, será manejada para proteger a criança. É justamente essa forma que lhe permitirá (re)existir. E nesse trânsito, descobrirá não ser o único. Ao abrir espaço para este protagonismo, o autor - de sua instância também em deslocamento - abre espaço para uma comunidade, alegoria que nos leva a pensar nos desafios enfrentados por aqueles que rompem com identidades compulsórias em nossa sociedade, bem como visualizar a potência de transitar no diálogo com outros:

Eu me lembro bem. Meu caso não é único. Por não ser único, lembro. Neste tártaro dourado salgado hostil, farei minha parte e contarei um de nossos contos. De todos eles, conto o meu. A estória de como

\footnotetext{
7 Ao discutir como a população transgênera é reconhecida em nossa sociedade, Jorge Leite Júnior (2012, p. 559-560) constata: "Talvez, um dos grupos sociais que, atualmente, mais causem repulsa, medo, ódio e, ao mesmo tempo, curiosidade, espanto e desejo seja o das pessoas que transitam entre os gêneros e/os sexos. Herdeiro de um imaginário tão antigo quanto persistente que mescla discursos vindos da religião à criminologia, da medicina à política, o discurso da monstruosidade, com toda a imprecisão conceitual, parece ser um dos organizadores dessa discussão”.
} 
me tornei tubarão. Devo contá-la, pois meu conto também é outros (DeLucA, 2017, p. 7).

Porém, não se trata de um procedimento harmônico e simples, muito pelo contrário. Como definiu Kafka, escrever para os judeus de Praga e Varsóvia - minoria identitária, que vivia entre o desejo da manutenção do tcheco e a opressão da língua maior, a língua alemã era "o beco sem saída que barr[ava] [...] o [seu] acesso à escritura e que f[azia] da literatura deles algo impossível" (Deleuze; GuATtaRI; 1977, p. 25). No entanto, é desse beco, é no tropeço com a impossibilidade de não escrever e de escrever numa língua/linguagem do Outro, que emergem - tanto lá, quanto aqui - escrituras que tem origem em uma batalha literária em que tudo é político:

Seu espaço exíguo faz com que cada caso individual seja imediatamente ligado à política. $\mathrm{O}$ caso individual se torna então mais necessário, indispensável, aumentado ao microscópio, na medida em que uma outra história se agita nele (DELEUZE; GUATTARI, 1977, p. 26).

Como na literatura kafkiana, aos moldes discutidos pelos filósofos franceses, no romance de DeLuca o caso individual é aumentado ao microscópio, o da criançatubarão, o que nos permite pensá-la como parte de um programa político, que vem à tona para fazer sentença de vida a uma população deslegitimada. Sob essa perspectiva, como os filósofos entendem que a literatura menor acaba por permitir uma enunciação coletiva e revolucionária e, por esse meio, o escritor, que está à margem, "se colo[ca] ainda mais em condição de exprimir uma outra comunidade em potencial, de forjar os meios de uma outra consciência e de uma outra sensibilidade" (Deleuze; Guattari, 1977, p. 27).

Essa dimensão é considerada por DeLuca na construção da arquitetura de seu romance, conforme revela em entrevista a Fernando Andrade: "O sexo dos tubarões é uma fábula de formação que transita entre aprender a escutar e viver o primeiro amor, aprender a falar e descobrir o próprio corpo, da exclusão e da violência até o reconhecimento da comunidade, do pertencimento" (DeLucA, 2018).

Esse gesto vincula sua obra ao político de forma potencializada no sistema literário brasileiro contemporâneo, uma vez que irrompe em contraponto a uma predominância de protagonistas e signos historicamente fortalecedores do statu quo de uma sociedade patriarcal, branca e cisheteronormativa (DALCASTAGNÈ, 2012; Frederico, 2016). ${ }^{8}$ Assim, mesmo que via de regra, a "literatura maior" brasileira

\footnotetext{
8 Um dos pontos discutidos, "por exemplo, é o fato de que de 1990 a 2004 de todos os romances publicados pelas principais editoras do país, $72,7 \%$ dos autores eram homens (esse número caiu para 70,6\% no período de 2005 a 2014); 93,9\% brancos (de 2005 a 2014 esse índice subiu para 97,5\%), mais de 6o\% deles vivem nos estados do Rio de Janeiro ou São Paulo (percentual mantido de 2005 a 2014). Concluindo, o escritor de literatura brasileira contemporânea é homem, branco, de classe
} 
contemporânea, continue perpetuando os valores de uma "sociedade maior", é indiscutível que essa cartografia - a passos curtos - tem se alterado nos últimos anos. Essa mudança pode ser explicada tanto pelo nascimento de editoras engajadas em publicar escritores/escritas marginalizadas, quanto pelo interesse por parte da crítica literária em discutir essa produção em seu contexto (DIAs, 2013).

Dessa forma, se para Franz Kafka e seus "iguais" de Praga e Varsóvia, o acesso à escritura enfrentava muitas impossibilidades; na contemporaneidade, em nosso país, muitos obstáculos também se estabelecem para as minorias identitárias, em especial, para a população transgênera, que ainda é narrada por uma língua/linguagem que sequer os reconhece como sujeitos de humanidade (Leite Júnior, 2012; Simakawa, 2015). Assim, DeLuca, aos moldes de Kafka, assume as impossibilidades como um tropeço e, por meio de uma textualidade própria, conta um conto que não é só seu: "Percebi que Bê falava minha língua. E que gosto bom tem quando se encontra alguém que fala sua língua. Faz da carne do mundo mais gostosa" (DeLucA, 2017, p. 46).

Quanto ao trabalho de reterritorialização da língua/linguagem do Outro, na entrevista já citada, a autora afirma seu engajamento político e estético na construção de sua literatura, que aqui se faz devir na mesma medida que a personagemprotagonista-narradora vivencia a sua travessia-transição:

Rejeitei categoricamente o masculino neutro universal, mas tampouco queria apenas o feminino. Eu não queria nenhum dos dois, ao mesmo tempo que queria todas as possibilidades entre um e outro, uma linguagem na qual todos coubessem. Diante disso tudo, o "eu" já era limitação suficiente. [...] Eu precisava (literária e pessoalmente) dessa linguagem sem gênero, desse tensionamento do dizer que se deforma enunciados simples e gera estranhamentos, também cria novas formas de falar, mais abertas. Uma linguagem imprevista para trajetórias imprevistas (DeLucA, 2018).

Consciente do seu papel de forjador de outra sensibilidade, em sua obra, o escritor usa a tessitura narrativa tanto para rasurar a marcação binária de gênero das personagens - de modo especial a da criança que transita tubarão, voz narradora; e a de Bê, seu par romântico, explicitamente identificados na narrativa -, como a linguagem que narrará essa experiência, suas descobertas; signos de deslocamento e fluidez de infinitos inimagináveis, cujas "palavras pare[cem] se lançar para impossíveis quedas” (DeLucA, 2017, p. 49).

Estamos, portanto, diante de uma escrita que não sucumbe ao problema insolúvel de enunciar o infinito; de enunciar uma existência para a qual ainda não há

média-alta e vive no eixo Rio-São Paulo. É essa centralização do discurso, apresentada como problema na diversidade (falta dela) de vozes também na construção de personagens, narradores, situações e na reafirmação ou reapresentação constante de preconceitos e posições, políticas inclusive" (FrEDERICO, 2016, p. 22). 
vernáculo. Será exatamente do predeterminado como insolúvel - sob uma língua nacional, que de forma estrutural e estruturante, se funda em binarismos, oposições, essencialismos e fixidez - que nascerá sua poética: a da errância (DeLucA, 2017, p. 37). Uma poética em que corpo e escritura passam a existir como se reconhecem, conforme nos diz a criança-tubarão:

Eu era o início de muitos infinitos. Todos azuis começavam e terminavam em mim. Naquele momento experimentei a felicidade. Recuperei algo de mim fundador: a gratidão por estar. Não me senti mais com a centelha que se perdeu da fogueira. Achei-me. Compreendi. Eu estou eu: eu sou aqui. Seria simplesmente. E, assim, nunca mais senti o exílio. Fazia parte da imensidão, ela eu sempre seria (DeLucA, 2017, p. 40).

Destaca-se, inclusive, que a transição identitária da criança, iniciada em terra, não se finda, em oposição, na forma tubarão no mar, pois as experiências vividas em comunidade, nas vastas e profundas águas oceânicas, abrirão caminhos para outras infinitudes. O existir, portanto, não se territorializa no ser, mas no estar e dessa forma se faz signo em choque com os padrões essencializadores da experiência identitária:

Toda vez que para mim tentava descrever as sensações que me dava a engolir, não encontrava as palavras que as completavam. $\mathrm{O}$ vocabulário parecia encolher o que sentia. Não bastava transformar tubarão em palavras. Isso perdura até hoje (DeLucA, 2017, p. 55-56).

O conto da criança, que não é só o seu, torna-se indispensável, porque - nessa mesma medida - permitirá que uma comunidade em formação, da terra ao mar, venha à superfície, se (re)construir como sobreviventes (re)existentes:

Nós, que conhecíamos a solidão, o desprezo, a violência. Nós, que para ser tivemos de nos tornar outra coisa que ninguém ensina. Que tanto lutamos para encontrar as palavras que nos digam de todo, sem sucesso. Nós que vemos o mundo esmagado pro seus olhos fechados (DeLuCA, 2017, p. 62).

Esse conto-espaço permite, assim, que essas vidas-corpos "monstros" narrem suas próprias histórias, ainda que não encontrem palavras que lhes "digam de todo"; ainda que precisem (re)criar o vernáculo preexistente (ButLER, 2017). Dessa forma, escritura e corpo-identidade, simultânea e ambivalentemente, revelam-se como devir no que dizem e no como dizem - e dessa instância fratura de fixidez, essencialismos:

Escrever é um caso de devir, sempre inacabado, sempre em via de fazer-se [...]. É um processo, [...] uma passagem de Vida que atravessa o vivível e o vivido. A escrita é inseparável do devir: ao escrever, estamos num devirmulher, num devir-animal ou vegetal, num devir-molécula, até num devirimperceptível (DeLEUZE, 1997, p. 11). 
Como consequência, também nos deparamos com uma literatura vida-saúde, que, ao nascer do enfrentamento com o statu quo, revela-se como diferença capaz de libertar a vida daquilo que a aprisiona. Assim, a escritora, cumprindo com este propósito, faz do espaço literário um mar capaz de abrigar infinitudes, entre elas, as de crianças-tubarão, que abjetificadas e monstrificadas - tal como as pessoas transgêneras -, rompem com o império de morte estabelecido para suas vidas; fazendo dessa travessia uma experiência humana vivível e vivida:

Mas meu tubarão me ninava com uma cantiga estranha que dizia de dia é menina e de noite é tubarão. Um dia, então, tive de me dizer, tive de admitir é, sou tubarão. [...] Concordar com ele me trouxe imenso alívio. Quando revelei, ele assentiu e disse que poderíamos, então, viver em tranquilidade até que eu sentisse vontade de ser tubarão no mar (DeLucA, 2017, p. 21).

Interessante notar, nesse trecho, talvez o único no romance, que a criança ainda que se enuncie a partir do marcador de gênero feminino, faz na rasura: de dia é menina e de noite já é tubarão. Destaca-se, sobretudo, que a criança-menina só ganhará saúde-vida ao descobrir-se em comunidade a qual pode se vincular, com a qual se identificará:

Corriam pelo corpo da rocha, se abismavam e, então, caiam. Foi este precipício que me contou a estória do primeiro tubarão. Vi pedaços. Fragmentos de papel que se debatiam em vento. Sabe-se muito pouco sobre o primeiro tubarão, compreendi. No entanto, ele estava ali. Vi primeiro salto: a primeira criança que pulou para o mar. Que se tornou tubarão. Antes de tudo, esse tubarão era uma pergunta. Dessa pergunta, se fez um belo sonho. Guarda a história dos tubarões. Guarda as crianças (DeLucA, 2017, p. 50).

À beira desse precipício, Bê, tubarão há mais tempo, instiga: "Fale com qualquer um. Qualquer tubarão. Aproveite a travessia. Conheça os teus" (DeLucA, 2017, p. 84). No entanto, ser ouvido e falar, não se constituía como um simples gesto a quem nunca fora ouvido, tampouco convidado a falar: "Nunca soube. Nunca pude me aproximar sem que me chamassem. Minha presença sempre me pareceu impossível. Imposição inoportuna. Como pressupor que alguém gostaria de me ouvir?” (DeLucA, 2017, p. 84). Essa é uma questão potente da escritura nessa obra, uma vez que, no trânsito de gênero-espécie, junto à Bê, também transitará do silenciamento à fala, constituindo-se dialogicamente (SPIVAK, 2010). Nesse processo de reconhecimento, a afetividade, outra marca dessa poética, também se revela revolucionária, pois faz viver:

Quando nossos corpos não tocavam mais o oceano, gargalhamos. Voávamos cada vez mais o oceano, gargalhamos. Voávamos cada vez mais alto. 
Vento nos secava e carregava. A curva do mundo se dobrava para nós. Sem asas, nosso voo era um planar contente. Até os astros nos sorriam. Eu e Bê dividimos o mundo todo (DeLucA, 2017, p. 106).

Nesse trecho, visualizamos um forte coeficiente de modificação da linguagem por meio de uma poética que abriga contrários e, por esse meio - delirante -, mostra que não há impossíveis: tubarões voam alto, ainda que sem asas; a curva se dobra e até os astros sorriem. Linguagem que se faz meio para outras possibilidades e nesse sentido multiplicadora de existências, de existir. Interessante notar que, se por um lado, o salto do precipício e os fragmentos de papel se enunciam como possibilidade de um (re)existir, também nos permitem experimentar a sensação da solidão - "queda livre" imposta a essas vidas:

Ouviu a lágrima que contou as pernas de uma criança, abertas à força e o som de lâmina mutilando. Sangue fluindo, jorrando: era a própria possibilidade de alegria que escorria vermelha do corpo. Ouviu o cheiro de sopa de legumes e de chão limpo com cândida, viu uma criança que lutava para se esconder entre palavras que não poderia ouvir. Viu uma criança que nas teclas do piano consolava a solidão de menina antiga. [...] Escutou outra mãe cuja mãe jamais lhe deu a mão. E também aquela cujos bicos dos seios foram arrancados como alicates. E outro conto onde bolhas de sabão flutuavam e aquela criança tinha certeza de que dentro levavam parte se sua alma (DeLucA, 2017, p. 65).

Nesse trecho, além de ouvirmos as dores e traumas experienciados por quem existe na diferença, também nos aproximamos de suas sensações igualmente "em queda livre". Por um lado, por meio de uma linguagem metafórica, revela-se o estupro de uma criança, por outro, é possível flutuar em paradoxos, trânsitos de uma linguagem criada para deslocar sentidos e sensações: ouvir lágrimas; cheirar sopa; ver palavras ditas. E nesse exíguo espaço potentemente político, entre as teclas de um piano - preto e branco - uma criança violentada, perseguida e solitária é acolhida.

Assim, por meio de uma textualidade fluida, como as águas do mar, DeLuca (2017) parece fazer de suas próprias lembranças "a origem ou a destinação coletivas de um povo por vir ainda enterrado em suas traições e renegações" (DELEUzE, 1997, p. 8). Instala-se uma fabulação em que o devir-outro se revela como possibilidade de uma vida vivível e enlutável (BUTLER, 2015):

Quando morre um tubarão, não cessa somente sua existência, morre também um mundo. Uma coleção singular de paisagens e contos. Morrem as lembranças e seus gostos. Morre cada cheiro, apaga-se o mapa. Morre um elo maravilhoso na corrente do tempo. A cada tubarão que nos arrancam, nos levam uma parte irrecuperável de nosso existir. Nos levam os amores e prazeres. Nos levam as memórias e a própria vontade de lembrar (DeLucA, 2017, p. 90). 
Dessa forma, subversivamente, a narrativa se estabelece em contraposição a uma realidade capaz de capturar tubarões, arrancá-los do mar e do amor e depois fazer: "Uma imensa pira [...] para queimar seu corpo já morto, já sufocado. Quei[mar] sua vida mesmo que essa já tivesse partido" (DeLucA, 2017, p. 103). Assim, existir tubarão, existir na diferença, instala-se como convite para sensações e desejos outros: "Alegria me tomou de repente. Aonde quer que meus olhos vissem, viam tubarão. Viam eu. E tantos vocês. Nós: a melhor das paisagens. Eu fazia a travessia do pertencer. Era em paz que persistia" (DeLuCA, 2017, p. 83). Além: revela, nesse conto e no contar, tubarões como sujeitos de afeto e amorosidade:

E, então, eu vi. Abaixo do banquete, os tubarões se tocavam. Seus corpos se encontravam, se roçavam. Fincavam de leve seus dentes nas costas uns dos outros. Os arranhões pareciam esboçar mapas. Mapas não previstos em nenhum código. Não se contorciam, não era violência. Era adoração. Se encontravam (DeLucA, 2017, p. 15).

Nessa narrativa, corpo e escrita "transubstanciam-se" num veículo de "afecto, intensivo, uma intensidade cumulativa que marca unicamente o limiar de uma sensação, o despertar de um estado de consciência" (Deleuze, 1997, p. 58) para outros devires, desnudando tanto a conquista do direito de tornar-se outro na vida, quanto o direito de narrar-se na singularidade.

Deleuze e Guattari (1977) afirmam que o escritor de uma literatura menor usa a língua artificial, a língua de papel para criar o seu próprio patoá. É o que vislumbramos na escrita de $O$ sexo dos tubarões, que usa desse exíguo espaço para fazer dizer as múltiplas dores e agonias de quem vive o abandono à própria sorte, de quem carrega em sua estória e em seu corpo marcas indeléveis de violência infligidas pelo homem animalizado.

Aos moldes deleuzianos, DeLuca faz do gesto de escrever "como um cão que faz seu buraco, um rato que faz sua toca”. Produz uma escrita que se faz no encontro de "seu próprio ponto de desenvolvimento, seu próprio patoá, seu próprio terceiro mundo, seu próprio deserto". (Deleuze; Guatarri, 1977, p. 28). DeLuca produz uma literatura que "invoca essa raça bastarda oprimida que não para de agitar-se sob as dominações, de resistir a tudo o que esmaga e aprisiona e de, como processo, abri[ndo] um sulco para si na literatura" (Deleuze, 1997, p. 15). Traz à tona uma forma de vida que transita e, desse lugar, diz o indizível por meio "[d]o delírio que as inventa, como processo que arrasta as palavras de um extremo a outro do universo. [Como] acontecimentos na fronteira da linguagem” (Deleuze, 1997, p. 9).

\section{Referências}

Butler, Judith. Corpos que pesam: sobre os limites discursivos do sexo. Tradução de Tomaz Tadeu da Silva. In: Louro, Guacira Lopes (Org.). O corpo educado. Belo Horizonte: Autêntica, 2001. p. 151-172. 
Butler, Judith. Problemas de gênero: feminismo e subversão da identidade. Trad. Renato Aguiar. Rio de Janeiro: Civilização Brasileira, 2017.

Butler, Judith. Quadros de guerra: quando a vida é passível de luto? Tradução de Sérgio Lamarão e Arnaldo Marques Cunha. Rio de Janeiro: Civilização Brasileira, 2015 .

CIDH - Comissão Interamericana de Direitos Humanos. Violência contra pessoas lésbicas, gays, bissexuais, trans e intersexo nas Américas. Washington: CIDH, 2015. On-line. Disponível em: http://www.oas.org/pt/cidh/docs/pdf/ violenciapessoaslgbti.pdf. Acesso em: 23 jan. 2015.

DALCASTAGnÈ, Regina. Literatura brasileira contemporânea: um território contestado. Rio de Janeiro: Editora da UERJ; Horizonte, 2012.

DeLuca, Naná. O sexo dos tubarões. São Paulo: Patuá, 2017.

DeLuca, Naná. Quatro perguntas para a escritora Naná Deluca. Entrevista a Fernando Andrade. Ambrosia, Rio de Janeiro, 2018. On-line. Disponível em: https: //ambrosia.com.br/literatura/quatro-perguntas-para-escritora-nana-deluca/.

Acesso em: 13 ago. 2018.

Deleuze, Gilles. Literatura e vida. In: Deleuze, Gilles. Crítica e Clínica. Tradução de Peter Pál Pelbart. São Paulo: 34, 1997. p. 11-16.

Deleuze, Gilles; Guattari, Felix. A literatura menor. In: Deleuze, Gilles; GuatTARI, Felix. Kafka por uma literatura menor. Tradução de Júlio Castanõn Guimarães. Rio de Janeiro: Imago, 1977. p. 25-42.

DIAS, Roberto Muniz. Editoras LGBTTT brasileiras contemporâneas como registro de uma literatura homoafetiva. 2013. Dissertação (Mestrado em Literatura) - Universidade de Brasília: Brasília, 2013.

Frederico, Graziele. Ausências e silenciamentos: a ética nas narrativas recentes sobre a ditadura brasileira. 2016. Dissertação (Mestrado em Literatura) - Universidade de Brasília, Brasília, 2017.

GGB - Grupo Gay Da Bahia. Assassinatos de LGBT no Brasil. Relatório 2016. Salvador: GGB, 2017. Disponível em: https://homofobiamata.files.wordpress.com/ 2017/o1/relatc3b3rio-2016-ps.pdf. Acesso em: 13 ago. 2018.

Jesus, Jaqueline Gomes. Orientações sobre identidade de gênero: conceitos e termos - Guia técnico sobre pessoas transexuais, travestis e demais transgêneros, para formadores de opinião. Brasília: Edição do Autor, 2012. On-line. Disponível em: https://www.sertao.ufg.br/up/16/o/ORIENTAÇÕES_POPULAÇÃO_TRANS. pdf?1334065989. Acesso em: 22 set. 2017.

LeITE JÚNIOR, Jorge. Transitar para onde?: monstruosidade, (des)patologização, (in)segurança social e identidades transgêneras. Rev. Estud. Fem., Florianópolis, v. 20, n. 2, p. 559-568, ago. 2012. Disponível em: http://www.scielo.br/scielo.php? 
script $=$ sci_arttext\&pid=So104-026X2012000200016\&lng $=\mathrm{pt} \& n r m=$ iso $>$. Acesso em: 13 jul. 2017. DOI: 10.1590/So104-026X2012000200016.

MombaçA, Jota. Pode um cu mestiço falar? Medium, Natal, 6 jan. 2015. On-line. Disponível em: https://medium.com/@jotamombaca/pode-um-cu-mestico-falare915edgc61ee. Acesso em: nov. 2018.

Oelsner, Miriam Bettina Paulina Bergel. A gênese do nacional-socialismo na Alemanha do século XIX e autodefesa judaica. 2017. Tese (Doutorado em História Social) - Universidade de São Paulo, São Paulo, 2017.

ReIs, Nilton; PINHo, Raquel. Gêneros não-binários: identidades, expressões e educação. Reflexão e Ação, Santa Cruz do Sul, v. 24, n. 1, p. 7-25, jan./abr. 2016. Disponível em: https://online.unisc.br/seer/index.php/reflex/article/download/7045/ pdf. Acesso em: 11 ago. 2018.

Rodovalho, Amara Moira. O cis pelo trans. Revista Estudos Feministas, Florianópolis, v. 25, n. 1, jan./abr. 2017. On-line. Disponível em: http://www.scielo.br/ scielo.php?script=sci_arttext\&pid=So104-026X2017000100365\&lng=en\&tlng=en . Acesso em: 11 ago. 2018. DOI: 10.159o/1806-9584.2017v25n1p365.

Simakawa, Viviane Vergueiro. Por inflexões decolonais de corpos e identidades de gênero inconformes: uma análise autoetnográfica da cisgeneridade como normatividade. 2015. Dissertação (Mestrado em Cultura e Sociedade) - Universidade Federal da Bahia, Salvador, 2015.

SpIvak, Gayatri. Pode o subalterno falar? Tradução de Sandra Regina Goulart Almeida, Marcos Pereira Feitosa e André Pereira Feitosa. Belo Horizonte: Editora da UFMG, 2010.

STF reconhece direito de transexuais mudarem nome sem necessidade de cirurgia. Rede Brasil Atual, São Paulo, $1^{\circ}$ mar. 2018. On-line. Disponível em: https://www.redebrasilatual.com.br/cidadania/2018/o3/stf-reconhece-direitode-transexuais-mudarem-nome-no-registro-civil-sem-necessidade-de-cirurgia. Acesso em: 11 ago. 2018.

Zızek, Slavoj. Violência: seis reflexões laterais. São Paulo: Boitempo, 2014.

Recebido em 30 de agosto de 2018.

Aprovado em 9 de abril de 2019.

\section{Resumo/Abstract/Resumen}

O sexo dos tubarões, de Naná DeLuca, ou uma escrita que faz delirar

\section{Leocádia Aparecida Chaves}


Analisaremos o romance $O$ sexo dos tubarões, de Naná DeLuca (2017), a partir dos conceitos de literatura menor, desenvolvido pelos teóricos Gilles Deleuze e Félix Guattari (1977), e de literatura como vida/saúde, discutido por Gilles Deleuze (1997). Chaves de leitura que nos parecem apropriadas para analisar uma arquitetura que desterritorializa a língua maior - o português brasileiro, territorializada no padrão cisgênero heteronormativo - para narrar o conto de um trânsito identitário: o de criança para tubarão, animal estigmatizado e monstrificado pelo olhar humano. Trata-se de uma arquitetura narrativa cujo caso individual, aumentado microscopicamente, revela um povo que se agita por meio de um potente alegoria, que aos moldes deleuzianos, se constitui numa potente "máquina de expressão" numa sociedade LGBTfóbica.

Palavras-chave: literatura menor, literatura saúde, devir-outro, trânsito identitário, Naná DeLuca.

\section{O sexo dos tubarões, by Naná DeLuca, or Writing that Delights}

\section{Leocádia Aparecida Chaves}

We will analyse the novel O sexo dos tubarões [The Sex of Sharks] by Naná DeLuca (2017), based on the concept of minor literature developed by the theorists Gilles Deleuze and Félix Guattari (1977), and literature as life / health, discussed by Gilles Deleuze (1997). These seem to us to be appropriate keys to analyses a structure that deterritorialises the major language - Brazilian Portuguese, territorialised in the cis-gender heteronormative template - to tell a tale of identity transit: that of a child into a shark, an animal that has been stigmatized and viewed as a monster by humans. In this individual case the narrative structure is greatly magnified to reveal a people in movement through its use of an allegory which, in Deleuzian terms, becomes a powerful "machine of expression" in an LGBT-phobic society.

Keywords: minor literature, literature as health, becoming-another, identity transit, Naná DeLuca.

\section{O sexo dos tubarões, de Naná DeLuca, o una escritura que hace delirar}

\section{Leocádia Aparecida Chaves}

En este artículo se hará un análisis de la novela $O$ sexo dos tubarões (El sexo de los tiburones), de Naná DeLuca (2017), a partir del concepto de literatura menor propuesto por los teóricos Gilles Deleuze y Félix Guattari (1977), así como del concepto de literatura como vida/salud elaborado por Gilles Deleuze (1997). Éstas claves de lectura nos parecen apropiadas para analizar una arquitectura que desterritorializa la lengua mayor - el portugués brasileño, territorializado en el estándar heterocisnormativo - para narrar el cuento de un cambio y tránsito identita- 
rio: de niño a tiburón, un animal estigmatizado y monstruoficado por la mirada humana. Se trata de una arquitectura narrativa cuyo caso individual, aumentado microscópicamente, hace visible un pueblo que se agita a través de una potente alegoría, que, a la manera deleuziana, constituye una potente "máquina de expresión” frente a una sociedad LGBTfóbica.

Palabras clave: literatura menor, literatura salud, devenir-otro, tránsito identitario, Naná DeLuca. 